Article

\title{
Study on Factors Affecting the Agricultural Mechanization Level in China Based on Structural Equation Modeling
}

\author{
Wei Li, Xipan Wei, Ruixiang Zhu and Kangquan Guo * \\ College of Mechanical and Electronic Engineering, Northwest A\&F University, Yangling 712100, China; \\ liweizibo@163.com (W.L.); xipanwei@nwsuaf.edu.cn (X.W.); zrxjdxy2006@sohu.com (R.Z.) \\ * Correspondence: jdgkq@nwsuaf.edu.cn; Tel.: +86-159-2931-7953
}

Received: 1 November 2018; Accepted: 17 December 2018; Published: 21 December 2018

\begin{abstract}
The subsidy policy for the purchase of agricultural machinery and China's Agricultural Mechanization Promotion Law have been implemented since 1998 and 2004, respectively. The goal of the policy and the law is to improve the agricultural mechanization level (AML) in China. Policymakers expect that the AML could be increased by improving the agricultural equipment level (AEL). The AML in China is affected by many factors. However, only a few studies have investigated the effects of the AEL on the AML. To fill this gap, we built an integrative conceptual framework and estimated a corresponding structural equation model (SEM) using the relevant data collected from 30 provinces (cities and districts) in mainland China. The relevant data cover the years from 2001 to 2014. There are six factors in our framework, including AEL, level of economic development, land resource endowment, benefit factors, policy and environmental factors, and demographic factors. The results showed that the AEL had the greatest impact on the AML. The level of economic development, the demographic factors, and the benefit factors not only directly affected China's AML but also indirectly affected the AML through the AEL. Meanwhile, land resource endowment and policy and environmental factors had only an indirect effect on the AEL. This report can be used to inform the government that the improvement of the AEL is one of the important ways to achieve the comprehensive mechanization of China's agriculture, that the agricultural machinery purchase subsidies must still be enhanced and that the enforcement of China's Agricultural Mechanization Promotion Law must still be strengthened.
\end{abstract}

Keywords: agricultural mechanization level; agricultural equipment level; affecting factors; subsidy policy for purchase; structural equation modeling; China

\section{Introduction}

Agricultural mechanization is an important symbol of agricultural modernization, and agricultural equipment is the carrier of agricultural modernization and thus an important tool used to promote agricultural mechanization [1]. The implementation of China's Agricultural Mechanization Promotion Law in 2004 and the subsidy policy for the purchase of agricultural machinery in 1998 have played especially significant roles in improving the agricultural equipment level (AEL) and the agricultural mechanization level (AML) [2]. From 2000 to 2014, the level of the comprehensive mechanization of crop cultivating, sowing, and harvesting in China increased from $32.3 \%$ to $61.6 \%$, with an average annual increase of $2.25 \%$. The total power of agricultural machinery during this period increased from 525 million kilowatts to 1081 million kilowatts, with an average annual increase of $5.71 \%$. China's basic national conditions are that there are more people and less land available than ever before, with less than 0.1 ha of cultivated area per person, approximately 0.63 ha per 
rural laborer, and low farmer income levels [3]. These conditions effectively prevent China from following the development path of using large-scale agricultural machinery, like that purchased by farmers in European and American countries. Correspondingly, China cannot follow the path of using small-scale agricultural machinery with higher value, like that purchased by Japanese and Korean farmers. With the development of agricultural mechanization, however, China has explored its own road to mechanization.

China's agriculture has experienced a large expansion of machine investments by farmers and machine rental services provided by specialized agents, which has contributed to the mechanization of agricultural production [4-6]. Previous literature on the agricultural mechanization in China has concluded that the agricultural mechanization has increased the grain yield and ensured food security in China [7-9]. At present, the agricultural mechanization in China is in the transition period from whole process mechanization to comprehensive mechanization [10]. The development of agricultural mechanization was consistent with China's new-type urbanization [11]. Because of the continuous advancement of China's urbanization process and the massive transfer of rural labor, China's agriculture is developing toward a reliance on more machinery input [12]. The increase in non-agricultural wage rates has led to an expansion of self-cultivated land size, and scale economies are emerging in Chinese agriculture with mechanization [8]. The main problems in the development of China's agricultural mechanization are concentrated in the imbalance of regional and field development, and the incoordination of investment and service [4]; therefore, knowing which factors motivate the AML is of great importance.

Some studies have conducted sufficient research on the factors influencing China's AML [5,13-15]. These studies have found that the scale of farmland management, agricultural labor transfer, policies, farmers' income level, the development level of agricultural machinery industry, and the cost of using agricultural machinery products have had an important impact on the development of agricultural mechanization. These factors have combined to form a unique mechanism for promoting agricultural mechanization in China [2,14-17]. In addition to factors such as regional economic development, land resources, as well as policy and environment, the AML in a country depends on the improvement of its AEL $[7,18]$. The factors affecting the AEL have also been studied in existing literature [1,19-22]. Liu and Tian [1] found that the level of economic development is the most important factor affecting the AEL in China, followed by the scale of farmland management and the agricultural planting structure. Yan [23] also reached similar conclusions.

Although some studies have investigated the factors that influence the AML in China, the effect of the AEL has not been studied in previous literature. Furthermore, the effects of various factors on the AML have not been studied in an integrated analytic framework. A typical single indicator or subjective weighting method is usually adopted to integrate multiple indicators into one indicator. The dependent variable is also set to a single indicator, due to the limitations of the methods used. For example, one can use the total power of agricultural machinery per laborer or use the total power of agricultural machinery to express the AEL $[15,21]$, or use the weighted averages of $0.4,0.3$, and 0.3 to indicate the ploughing, seeding, and harvesting mechanization levels, respectively [24]. Such practices cannot fully reflect the AEL and AML. With these methods, we still need to obtain information on the effect of the AEL on the AML, along with other essential factors that affect the AML, including the economy and technology, social-natural factors, the policy and environmental factors, and the benefit factors. We accomplished this by using structural equation modeling (SEM), which is a systematic analysis method that integrates factor analysis and path analysis. For example, SEM has the advantages of simultaneously processing multiple dependent variables, allowing independent variables and dependent variables to contain measurement errors, estimating factor structures and factor relationships, and estimating the fitting degree of the whole model. In fact, SEM measures not only the relationship between measured variables and latent variables (variables measured by multiple indicators), but also the relationship between two latent variables. 
The purpose of this study was to estimate the effect of various factors, including the AEL on the AML in an integrated analytic framework. The results enabled us to understand the influence of the AEL on the AML, to help the policymakers and project implementers of agricultural machinery purchase subsidy policies further design and implement their policies and projects, thus promoting the continuous improvement of agricultural mechanization. The structure of the paper is as follows: Section 2 discusses the conceptual framework, followed by Section 3, which explains the materials and methods used in this study. Section 4 presents the results and discusses the findings, and the last section concludes the paper.

\section{Conceptual Framework}

The term AEL refers to the measurement of the holding quantity and technical level of agricultural machinery that applies to agricultural production [20]. AEL is divided into two indicators: aggregate indicators and average indicators. The aggregate indicators include the total power of agricultural machinery, the original value of agricultural machinery, and the total power of tractors, etc. Of these indicators, the total power of agricultural machinery is the most widely used. The average indicators include the total power of agricultural machinery per laborer or per hectare, as well as the original value of agricultural machinery per labor, and the total power of tractors per hectare. The term AML refers to the level of use of agricultural machinery to provide services for agricultural production. Agricultural mechanization can not only reduce farmers' labor intensity, but it can also improve agricultural economic efficiency and production efficiency levels, thereby reflecting the technical and management levels of agriculture [25]. AML relates to the integrated mechanical work level output during the ploughing, seeding, and harvesting of crops. The general method is to weight the proportion of the area of mechanical ploughing, mechanical seeding and mechanical harvesting, respectively, to the total sown area of crops by $0.4,0.3$, and 0.3 [26-30]. From the definition and measurement of the two indicators, it can be seen that the AEL is the basis of the AML. Thus, we propose:

Hypothesis 1. The AEL has a positive effect on the AML.

The economic development of a country can promote its AEL and the AML [31,32]. The higher the level of economic development, the stronger the investment capacity of agricultural machinery. The higher the opportunity cost of labor, the more frequently the labor-saving technologies will be used (i.e., to achieve mechanized operations through the purchase and employment of agricultural machinery). Thus, the higher the level of economic development in a region, the higher the AEL and AML [20,33]. The GDP per capita is an important indicator to reflect the level of regional economic development. The higher the GDP per capita, the lower the proportion of GDP in the primary industry will often be, as the favorable economic development environment and industrial structure have created the optimum conditions for the development of agricultural mechanization [24]. Farmers account for the main body of agricultural machinery investment, so the per capita net income of farmers is an important factor affecting the AEL and AML [22], because farmers in higher income areas are more capable of buying more advanced and more applicable agricultural machinery. Thus, based on the above view, we hypothesize:

Hypothesis 2. The level of economic development has a positive impact on both the AEL and AML. Among the indicators of economic development, the GDP per capita and the per capita net income of farmers are positively related to the AEL and AML. The proportion of the primary industry GDP that accounts for the regional GDP is negatively correlated to the AEL and AML.

Land resources provide the basic material conditions of agricultural production. The differences in land resources in terms of quantity, quality, and type determine the differences in agricultural production (production mode, crop type, farming system, etc.). Additionally, the development of agricultural equipment technology in different agricultural production types can have significant 
differences. Therefore, land resources can indirectly affect the AML through the AEL. The impact of land resources on the AEL is mainly manifested in the following three aspects. First, the scale of land management, the scale effect of agricultural mechanization, and unit operating cost advantages can only be fully manifested on large-scale land areas; the cultivated area per laborer is also usually used to reflect the scale of land management $[15,22]$. Second, with regard to the planting structure (i.e., the main types of crops), the development of the AEL differs, depending on the crop. For example, more and better agricultural equipment is used on wheat crops than that on rice crops. Therefore, the crop planting structure has a significant impact on the AEL [20]. Third, the natural land conditions play a role in the AEL. For example, it is easier to achieve mechanization in plains and other flat terrains than in hilly and mountainous areas. The development level of machinery technology in plains is also higher than in hilly and mountainous areas. Therefore, the larger the proportion of plains in one region, the higher the AEL. Based on the above view, we hypothesize:

Hypothesis 3. Land resource endowment is positively related to the AEL. That is, the area of agricultural cropping per laborer and the ratio of the area of sown wheat to the total sown area of crops are positively correlated with the AEL, and the ratio of hilly and mountainous area to the total land area is negatively correlated with the AEL.

In agricultural production, agricultural machinery and the agricultural labor force are in an alternative relationship. Therefore, the demographic factor in one region has an impact on that region's AEL and AML. First, the number of agricultural labor resources is considered. Under the circumstances where the area of cultivated land is certain, where there are fewer agricultural practitioners, and where the farmers are prosperous, the demand for agricultural machinery is greater, and the AML is higher $[22,33]$. Generally, the ratio of primary industry practitioners to society practitioners is used to measure the resource endowment of the agricultural labor force. Second, the transfer situation of agricultural labor force is considered. The process of urbanization in China has led to the transfer of agricultural laborers from rural to urban areas. The essence of agricultural mechanization is the substitution of capital for labor, and the degree of substitution depends on the relative scarcity of capital and labor. The more labor is transferred from agriculture to non-agriculture fields, the scarcer agricultural labor will become. Moreover, the demand for agricultural mechanization will be relatively strong, and then the AML will be improved [15,22]. The labor transfer rate is used to represent the transfer of agricultural labor in one region. Third, the knowledge or educational level of agricultural laborers is considered. If farmers have acquired a higher level of education, on the one hand, it is easier for them to grasp the advanced technologies, thus enhancing the AEL. On the other hand, higher education makes it is easier for them to find jobs, thus improving the operating level of agricultural mechanization. Based on the above view, we hypothesize:

Hypothesis 4. Demographic factors have an impact on both the AEL and AML. In other words, the transfer rate of labor and the educational degree of rural residents are in positive correlation to the AEL and AML. The ratio of primary industry practitioners to society practitioners is negatively correlated to the AEL and AML.

Favorable policies and a good environment have a positive effect on the development of agricultural machinery. The subsidy that can be used for purchasing agricultural machinery represents a very important policy in terms of benefiting farmers. Subsidies reduce the cost to farmers of purchasing agricultural machinery, enhance the demand for agricultural machinery, and increase the number of agricultural machines in use [34]. More importantly, such subsidies improve the AEL. Zhang et al. suggests that the average allowance of the cumulative amount of land per unit area over the years should be used to indicate the impact of purchasing subsidies on the AEL [33]. Second, the price of agricultural machinery products is considered. According to the supply and demand theory, the prices of agricultural machinery products directly affect the level of farmers' demand for agricultural machinery. Hou proposes the use of a fixed base price index of mechanized farm 
machinery to reflect the price of agricultural machinery products [15]. Third, the level of social services is considered. A good farm machinery socialization service level plays an important positive role in the promotion of the use of advanced agricultural equipment. The number of personnel engaged in agricultural mechanization technology, promotion, education, and training per 10,000 can be regarded as the ratio used to measure the service level [22]. Based on the above view, we hypothesize:

Hypothesis 5. Policy and environmental factors have an important impact on the AEL. That is, the average subsidy per unit area over the years, and the number of personnel engaged in agricultural mechanization technology, education, promotion, and training per 10,000 members of the labor force is positively related to the AEL. Conversely, agricultural machinery product price and AEL have a negative correlation.

Economic effect reflects whether mechanized operation is reasonable in the economy. It is also one of the prerequisites for the development of agricultural machinery. First of all, with the decline in the number of rural laborers, the saving cost and increasing benefit of agricultural machinery operations and the advantage of land scale have become more obvious [24]. The pursuit of agricultural production efficiency drives farmers to actively purchase or hire agricultural equipment for mechanized operations, thus improving the AEL and AML. Second, cross-regional operations not only promote the AML, but they also increase farmers' incomes and achieve good economic and social benefits. As a result, both the AEL and AML can be improved. Mechanized benefit indicators are expressed in terms of agricultural output per laborer and agricultural grain production per laborer. Based on the above view, we hypothesize:

Hypothesis 6. Benefit factors have an impact on both the AEL and AML. That is, agricultural output value per laborer and agricultural grain production per laborer are positively correlated to the AEL and AML.

Based on the hypotheses above, the hypothesis model regarding the factors affecting the AML is shown in Figure 1.

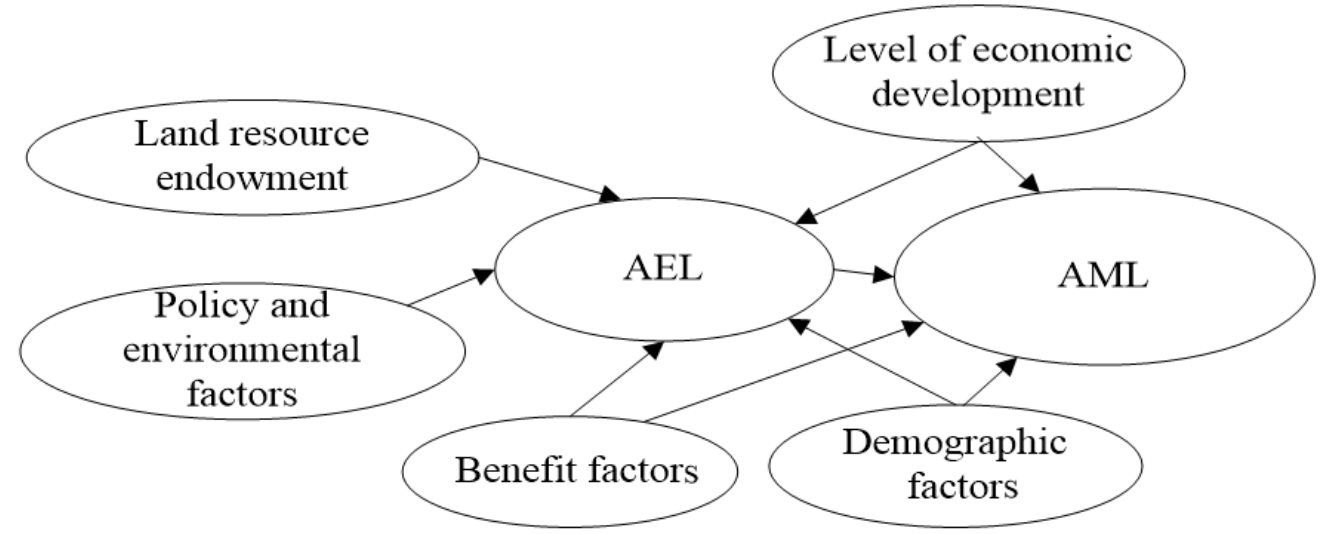

Figure 1. Hypothesis structural model of the factors affecting the AML.

\section{Materials and Methods}

\subsection{Data Sources}

Related data from 30 provinces (cities, districts) in mainland China, all from the years 2001 to 2014, were collected. Tibet is not included in the consideration, due to the lack of data. All the data used were sourced from the "National Agricultural Mechanization Statistical Yearbook", the "China Agriculture Mechanization Yearbook", the "China Rural Statistical Yearbook", and the "China Statistical Yearbook" over the years; the terrain data were sourced from the Chinese natural resources database. The data collection process and sources are shown in Table A1. The GDP per capita and agricultural output value per laborer were converted based on the GDP price index of provinces 
(cities, districts). The per capita net income of farmers was converted based on the consumer price index of rural residents, and the original value of agricultural machinery was converted based on the agricultural machinery price index. In order to eliminate the effects of different orders of magnitude and dimensions of different variables, the data of all variables were standardized. The method used in variables standardization is the $\min X-\max X$ standardization method. That is, all variables are transformed linearly. If $\operatorname{Min} X$ and $\operatorname{MaxX}$ are the minimum and maximum values of variable $X$, after standardization, $X^{\prime}=(X-\operatorname{Min} X) /(\operatorname{Max} X-\operatorname{Min} X)$. The latent variables and their measurement variable indexes are shown in Table 1 . In the hypothesis of SEM, it is necessary to reflect that the latent variable and each measurable variable are in positive correlation. Therefore, the variables in Table 1 that show a negative impact should use corresponding values after 1-standardization for calculation.

Table 1. Indicators of the AML and its affecting factors.

\begin{tabular}{|c|c|c|c|}
\hline Latent Variables & Measurable Variables & Variable Codes & Expected Sign \\
\hline \multirow{3}{*}{$\begin{array}{c}\text { Level of economic } \\
\text { development (ECON) }\end{array}$} & GDP per capita & AGDP & + \\
\hline & Per capita net income of farmers & INCO & + \\
\hline & Primary industry GDP/regional GDP & FGDP & - \\
\hline \multirow{3}{*}{$\begin{array}{l}\text { Land resource } \\
\text { endowment (LAND) }\end{array}$} & Cultivated area per laborer & CULT & + \\
\hline & Hilly and mountainous area/land area & HILL & - \\
\hline & Wheat sown area/total sown area of crops & WHEA & + \\
\hline \multirow{3}{*}{$\begin{array}{l}\text { Demographic factors } \\
\text { (DEMO) }\end{array}$} & $\begin{array}{c}\text { Primary industry practitioners/society } \\
\text { practitioners }\end{array}$ & FEMP & - \\
\hline & Labor transfer rate & TLAB & + \\
\hline & Educational degree of rural resident/year & EDUC & + \\
\hline \multirow{3}{*}{$\begin{array}{l}\text { Policy and } \\
\text { environmental factors } \\
(\text { POEN })\end{array}$} & $\begin{array}{c}\text { Average subsidy funds per unit area of land } \\
\text { over the years }\end{array}$ & SUBS & + \\
\hline & $\begin{array}{l}\text { The number of personnel engaged in } \\
\text { agricultural machinery technology, } \\
\text { promotion, education, and training per } \\
10,000 \text { labor force }\end{array}$ & TEMP & + \\
\hline & $\begin{array}{l}\text { Fixed base price index of mechanized farm } \\
\text { machinery }\end{array}$ & PRIC & - \\
\hline \multirow{2}{*}{ Benefit factors (BENE) } & Agricultural output value per laborer & OUTV & + \\
\hline & Agricultural grain production per laborer & YIEL & + \\
\hline \multirow{3}{*}{ AEL } & Total power of agricultural machinery & POWE & + \\
\hline & Original value of agricultural machinery & VALU & + \\
\hline & Total power of tractors & TRAC & + \\
\hline \multirow{3}{*}{ AML } & Mechanical ploughing level & MCUL & / \\
\hline & Mechanical seeding level & MSOW & / \\
\hline & Mechanical harvesting level & MHAR & / \\
\hline
\end{tabular}

Note: Labor transfer rate $=$ (rural workers - agricultural workers $) /$ rural workers; cultivated area per rural workers $=$ area cultivated $/$ rural workers.

\subsection{Estimation Approach}

The SEM method is a typical systematic analysis method, which integrates the linear models of many variables to measure the relationship between measured and latent variables, and between all latent variables $[35,36]$. The hypothesis model shown in Figure 1 is the SEM model, because the level of economic development, land resource endowment, policy and environmental factors, demographic factors, benefit factors, AEL, and AML are all latent variables. The SEM includes the measurement model and the structural model, of which the former reflects the relation between the latent variables 
and the measured variables, while the latter reflects the structural relation between latent variables, which is usually composed of three matrix equations, as follows:

$$
\begin{gathered}
X=\Lambda_{x} \xi+\sigma, \\
Y=\Lambda_{y} \eta+\varepsilon, \\
\eta=B \eta+\Gamma \xi+\zeta .
\end{gathered}
$$

Equations (1) and (2) are measurement models, $X$ and $Y$ represent the measured variable of the exogenous latent variable (the latent variable of the cause) and the measured variable of the endogenous latent variable (the latent variable of the result), respectively; $\Lambda_{x}$ and $\Lambda_{y}$ represent the correlation coefficient matrix between the exogenous latent variable and its measured variables, and between the endogenous latent variable and its measured variables, respectively. In addition, $\sigma$ and $\varepsilon$ represent residual terms, and Equation (3) is the structural model, where $\eta$ represents the endogenous latent variable, $\xi$ represents the exogenous latent variable, and they are connected through the coefficient matrixes $B$ and $\Gamma$, as well as the residual term $\zeta$.

\section{Results and Discussion}

In this study, Amos 18.0 (IBM, New York, USA) and SPSS18.0 (IBM, New York, USA) were used to estimate Equations (1)-(3), based on the standardized data. The maximum likelihood estimation (MLE) was used; MLE is the most commonly used method in SEM. In most cases, the parameter estimation obtained from the MLE is better than that of other methods [37]. The critical ratio (CR) of the multivariable index was 2.2361, which is less than the 5 recommended by Kline [38]. This finding indicated that the data of the observed variables satisfied the requirements of the SEM.

\subsection{Model Specification Tests}

\subsubsection{Individual Item Reliability Analysis}

The reliability test aims to test whether the measured variables have the required consistency and stability when measuring latent variables. Cronbach's $\alpha$ is the most commonly used reliability test indicator, and Hair et al. believes that it is acceptable for Cronbach's $\alpha$ to be greater than 0.7 for verification purposes [39]. However, a value greater than 0.8 is considered to be better. Table 2 shows that the Cronbach's $\alpha$ coefficient of the latent variables is between 0.72 and 0.81 , which is in line with the requirements of being greater than 0.7 , thus indicating that the reliability of the measurement model is good.

Table 2. Results of the reliability and convergent validity analysis.

\begin{tabular}{cccc}
\hline Latent Variables & Cronbach's $\alpha$ & Composite Reliability & $\begin{array}{c}\text { Average Variance } \\
\text { Extracted }\end{array}$ \\
\hline ECON & 0.7824 & 0.8050 & 0.5797 \\
LAND & 0.7695 & 0.7871 & 0.5521 \\
DEMO & 0.7607 & 0.7502 & 0.5009 \\
POEN & 0.7618 & 0.7495 & 0.5006 \\
BENE & 0.7262 & 0.6785 & 0.5135 \\
AEL & 0.7660 & 0.7621 & 0.5169 \\
AML & 0.8011 & 0.8197 & 0.6026 \\
\hline
\end{tabular}

\subsubsection{Convergence Validity Analysis}

The term "convergence validity" refers to a set of measurement variables that can be used to measure the same latent variable. Hair et al. argued that a latent variable must meet the following two conditions in order to have the appropriate degree of convergence validity: (1) the composite reliability 
should be greater than or equal to 0.6 , and (2) the average extraction variance should be greater than or equal to 0.5 [39]. There are seven latent variables in this study, namely, level of economic development, land resource endowment, demographic factors, policy and environmental factors, benefit factors, AEL, and AML. From Table 2, it can be seen that the composite reliability values and the average variance extracted (AVE) are in line with the standard set by Hair et al. This suggests that our measurement model has acceptable convergence validity.

\subsubsection{Discriminant Validity Analysis}

The discriminant validity analysis is used to test whether the measurement indexes of different latent variables are highly correlated. The AVE is the most commonly used method to check the discriminant validity of the SEM. A higher AVE indicates a higher degree of correlation between the measured indexes of the latent variables. If there is discriminant validity between latent variables, then the degree of correlation between the measurement indexes of the same latent variable is higher than the degree of correlation between the measurement indexes of different latent variables [40]. Since the AVE is a square value, the correlation coefficient of each latent variable must also be adjusted to the square unit. In this study, the square of the correlation coefficient and the AVE of the latent variables are shown in Table 3. As can be seen from the table, the AVE of each latent variable is greater than the squared value of the correlation coefficient of each latent variable, thereby indicating that the measurement model has good discriminant validity.

Table 3. Results of the discriminant validity analysis.

\begin{tabular}{|c|c|c|c|c|c|c|c|}
\hline $\begin{array}{c}\text { Latent } \\
\text { Variables }\end{array}$ & ECON & LAND & DEMO & POEN & BENE & AEL & AML \\
\hline ECON & 0.5794 & & & & & & \\
\hline LAND & 0.3053 & 0.5524 & & & & & \\
\hline DEMO & 0.3528 & 0.2360 & 0.5006 & & & & \\
\hline POEN & 0.1058 & 0.1042 & 0.0673 & 0.5012 & & & \\
\hline BENE & 0.2058 & 0.4529 & 0.0213 & 0.3987 & 0.5134 & & \\
\hline AEL & 0.3367 & 0.1656 & 0.1304 & 0.2303 & 0.3685 & 0.5164 & \\
\hline AML & 0.4130 & 0.2057 & 0.1561 & 0.2513 & 0.3547 & 0.4986 & 0.6027 \\
\hline
\end{tabular}

\subsubsection{Model Integrated Degree of Fitting Analysis}

A good model integrated degree of fitting is a necessary condition when SEM is applied as a theoretical model for verification [41]. The SEM method provides a variety of indicators. Each statistical indicator only reflects a certain degree of fitting, and the fitting index only provides the degree of fitting between the hypothesis model and the sample [38]. The results of the hypothesis model fitting for influencing factors of the agricultural mechanization are shown in Table 4. This table shows that the integrated fitting of the model is good, thereby indicating that the proposed causal relation model is consistent with the actual data. In addition, the path analysis hypothesis model in Figure 1 is also supported.

Table 4. Goodness-of-fit indexes of the final model.

\begin{tabular}{|c|c|c|c|c|c|c|c|c|c|}
\hline $\begin{array}{l}\text { Goodness-of-Fit } \\
\text { Index }\end{array}$ & $x^{2}$ & $\chi^{2} / \mathrm{df}$ & GFI & RMR & SRMR & RMSEA & NFI & IFI & RFI \\
\hline Evaluation standard & The smaller the better & $<3$ & $>0.9$ & $<0.05$ & $<0.05$ & $<0.08$ & $>0.90$ & $>0.90$ & $>0.90$ \\
\hline Actual value & 256.37 & 2.07 & 0.918 & 0.044 & 0.035 & 0.056 & 0.910 & 0.925 & 0.911 \\
\hline
\end{tabular}

Note: $\chi^{2} / \mathrm{df}$ represents Chi square degrees of freedom; GFI represents goodness-of-fit index; RMR represents the root mean-square residual; SRMR represents the standardized root mean-square residual; SRME represents the root mean-square error of approximation; NFI represents the normed fit index; IFI represents the incremental fit index; RFI represents the relative fit index. 


\subsection{Hypotheses Testing}

The SEM coefficient estimation diagram is shown in Figure 2; Table 5 shows the standardized path coefficients for the factors affecting the AML and the corresponding $t$-value.

\subsection{Discussion}

Based on the above results, our main general conclusion is that the AEL can be explained by the level of economic development, land resource endowment, benefit factors, demographic factors, and policy and environmental factors. The standard path coefficients of these factors toward the AEL are significant. The level of economic development is the economic basis for the improvement of the AEL, and the economic capacity of farmers has a particularly decisive effect on the AEL. In regions with high levels of economic development, the farmers have accumulated more funds. They have strong purchasing power when it comes to agricultural machinery. Therefore, the level of economic development makes the largest contribution to the improvement in the AEL [21]. The basis for the operation of agricultural machinery is the land resource. As any agricultural machinery is operated on a specific land resource, any differences in land resource endowment have a crucial impact on the AEL. Currently, the development of agricultural machinery technology applicable to different crops and different terrains in China is not balanced. The agricultural machines that are suitable for plains crops and wheat plantations are more highly developed than the machines used in hilly areas and on rice plantations. Therefore, land scale, crop type, topography, and other land conditions have an impact on the AEL. Having good economic benefits is a prerequisite for the promotion of agricultural machinery, and thus, the good benefits of agricultural mechanization can promote the improvement of the AEL. The improvement in the AEL partially depends on policies and the environment [15]. The subsidy policy that applies to the purchase of agricultural machines has not only promoted the development of the agricultural machinery industry, but the policy has, since 1998, also improved the promotion of more advanced agricultural machinery. As a result, more manual operations have been replaced by mechanical operations. Therefore, it is considered that demographic factors have the least impact on the AEL.

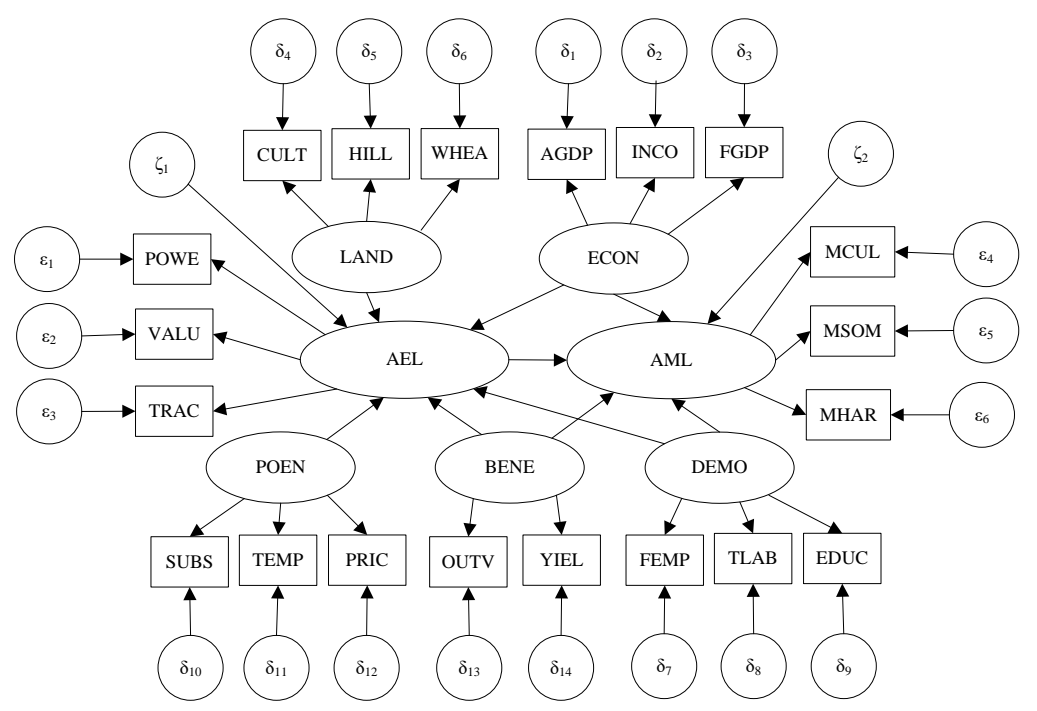

Figure 2. Structural equation modeling (SEM) path diagram. 
Table 5. SEM path coefficient and hypothesis testing.

\begin{tabular}{|c|c|c|c|c|}
\hline Model & Path & $\begin{array}{c}\text { Standardized } \\
\text { Coefficient }\end{array}$ & $t$-Value & Inference \\
\hline \multirow{9}{*}{ Structural model } & $\mathrm{ECON} \rightarrow \mathrm{AEL}$ & $0.5153^{* * *}$ & 4.3064 & Supported \\
\hline & $\mathrm{LAND} \rightarrow$ AEL & $0.4262 * *$ & 2.3246 & Supported \\
\hline & $\mathrm{DEMO} \rightarrow \mathrm{AEL}$ & 0.2038 * & 1.7675 & Supported \\
\hline & $\mathrm{POEN} \rightarrow \mathrm{AEL}$ & $0.2624 * *$ & 2.2762 & Supported \\
\hline & $\mathrm{BENE} \rightarrow \mathrm{AEL}$ & $0.3250 * *$ & 1.7859 & Supported \\
\hline & $\mathrm{ECON} \rightarrow \mathrm{AML}$ & 0.2754 * & 1.8953 & Supported \\
\hline & $\mathrm{DEMO} \rightarrow \mathrm{AML}$ & 0.1627 * & 1.7424 & Supported \\
\hline & $\mathrm{BENE} \rightarrow \mathrm{AML}$ & 0.2538 * & 1.6584 & Supported \\
\hline & $\mathrm{AEL} \rightarrow \mathrm{AML}$ & $0.6025^{* * *}$ & 5.2468 & Supported \\
\hline \multirow{17}{*}{$\begin{array}{l}\text { Measurement } \\
\text { model }\end{array}$} & $\mathrm{AGDP} \leftarrow \mathrm{ECON}$ & $0.7617^{* * *}$ & 5.4572 & Supported \\
\hline & $\mathrm{INCO} \leftarrow \mathrm{ECON}$ & $0.8134^{* * *}$ & 4.8506 & Supported \\
\hline & $\mathrm{FGDP} \leftarrow \mathrm{ECON}$ & 0.7068 & 1.5348 & Not Supported \\
\hline & CULT $\leftarrow$ LAND & $0.7584 * *$ & 2.3486 & Supported \\
\hline & HILL $\leftarrow$ LAND & 0.7461 * & 1.8453 & Supported \\
\hline & WHEA $\leftarrow$ LAND & $0.7242 * *$ & 2.2851 & Supported \\
\hline & $\mathrm{FEMP} \leftarrow \mathrm{DEMO}$ & 0.6588 * & 1.7767 & Supported \\
\hline & $\mathrm{TLAB} \leftarrow \mathrm{DEMO}$ & $0.7455^{* * *}$ & 4.1580 & Supported \\
\hline & EGUC $\leftarrow$ DEMO & 0.7162 * & 1.8746 & Supported \\
\hline & $\mathrm{SUBS} \leftarrow \mathrm{POEN}$ & $0.7628^{* * *}$ & 3.8525 & Supported \\
\hline & $\mathrm{TEMP} \leftarrow \mathrm{POEN}$ & 0.7124 * & 1.8644 & Supported \\
\hline & $\mathrm{PRIC} \leftarrow \mathrm{POEN}$ & 0.6421 & 1.2350 & Supported \\
\hline & $\mathrm{OUTV} \leftarrow \mathrm{BENE}$ & 0.7125 * & 1.6872 & Not Supported \\
\hline & $\mathrm{YIEL} \leftarrow \mathrm{BENE}$ & $0.7206^{*}$ & 1.8024 & Supported \\
\hline & $\mathrm{POWE} \leftarrow \mathrm{AEL}$ & $0.7564^{* * *}$ & 6.3001 & Supported \\
\hline & $\mathrm{VALU} \leftarrow \mathrm{AEL}$ & $0.7141^{* *}$ & 2.3420 & Supported \\
\hline & TRAC $\leftarrow$ AEL & 0.6845 & 1.3425 & Not Supported \\
\hline
\end{tabular}

Note: ${ }^{* * *}$ indicates a significance level of $1 \%,{ }^{* *}$ indicates a significance level of $5 \%$, and ${ }^{*}$ indicates a significance level of $10 \%$.

The results show that the AML can be affected by the level of economic development, benefit factors, demographic factors, and AEL. Agricultural equipment is not only the material basis for agricultural mechanization, but also the "pushing force" of agricultural mechanization operations. The AEL is the Granger cause for the increase in the AML. For each one unit increase of agricultural equipment, the AML will increase by 0.2921 units [42]. The level of economic development is considered to be the "pulling force" for the development of agricultural mechanization. In a region with high levels of economic development, farmers tend to have higher requirements for their life comforts. As such, their demands for agricultural machinery are usually greater, which in turn can drive the improvement in the AML. The benefits of mechanized operation have prompted farmers to use agricultural machinery to engage in agricultural production, and correspondingly, the AML is driven to rise continuously. In general, if there are relatively more agricultural laborers in a certain region, then farmers' demands for agricultural machinery operations will be relatively weak. Thus, the AML will be low. However, due to the transfer of rural laborer surpluses and the "multi-business" behavior of farmers, the demographic factor actually has the lowest impact on the AML. 
The results from our study confirm that the per capita net income of farmers is the most significant factor affecting both the AEL and AML. Farmers are the main investors in agricultural equipment, and the per capita net income of farmers is an important reflection of farmers' investments capacity. The GDP per capita reflects not only the level of economic development and farmers' agricultural machinery purchasing power, but also the local economy's investment capacity in terms of agricultural machinery. The dependence of the development of agricultural mechanization on financial investment is positively correlated to economic development [43]. According to the economic development theory proposed by American economist S. Kuznets, the industrial share of the primary industry shows a downward trend in line with the development of the regional economy. For example, Beijing, Tianjin, and Shanghai, cities with high levels of economic development, usually have low primary industry GDP as a proportion of regional GDP. Meanwhile, economically underdeveloped provinces, such as Guizhou, Jiangxi, and Anhui, usually have higher primary industry GDP in terms of regional GDP. However, the subsidy policy to purchase agricultural machines in recent years has mostly been applied to major grain-producing provinces, which has resulted in the insignificant impact of the proportion of primary industry GDP in terms of regional GDP on both the AEL and AML.

Our findings indicate that the agricultural cultivated area per laborer, the proportion of wheat sown area in the total sown area of crops, and the proportion of hilly and mountainous land areas all have a significant effect on the AEL. The more area there is for farmers to cultivate, the greater the ability to highlight the scale effect of agricultural machinery operations, and the more farmers are willing to invest in agricultural machinery and therefore, the higher the AEL. The development level of the agricultural machinery industry is the basis of the AEL. Generally, the development level of the wheat agricultural machinery industry is higher than that of the rice agricultural machinery industry. The development level of the agricultural machinery industry in the plains is higher than in hilly and mountainous areas. Therefore, the regions with a higher proportion of wheat planting area and a smaller proportion of hilly and mountainous areas usually have a higher AEL.

We found that the effects of agricultural output value per laborer and agricultural grain production per laborer on both the AEL and AML are significant. First of all, with the decline in the quantity and quality of agricultural laborers, the popularization of advanced technology is bound to take agricultural machinery as the material carrier, in order to achieve good economic benefits. Second, in order to promote the sustainable and healthy development of the rural economy and ensure the effective supply of grain and other major agricultural products, higher requirements are proposed with respect to the agricultural equipment support capacity, as well as for driving the new demand for agricultural machinery and new spaces to promote the AML [44]. In addition, a series of advanced applicable technologies (such as subsoiling technology, deep fertilizing, conservation tillage, and efficient plant protection) have achieved good economic, social, and ecological benefits. These technologies have also been used on agricultural machinery products and mechanized operations.

Our results corroborate several findings of prior studies [45,46]. However, our findings are also in contrast with other research results. Our study confirms that the average subsidy funds per unit area of land and the number of personnel engaged in agricultural mechanization technology, promotion, education, and training per 10,000 people all have a significant impact on both the AEL and AML. Meanwhile, the influence of the price of agricultural machinery products is not significant. The implementation of the agricultural machinery purchase subsidy policy has improved the contribution rate of the supply and demand equilibrium in the agricultural machinery market [45], stimulated the enthusiasm of farmers to purchase agricultural machinery, and effectively promoted the improvement in the AEL. The rapid development of agricultural mechanization is inseparable from a large number of professionals. The more professionals are engaged in agricultural mechanization technology, promotion, education, and training per 10,000, the richer will be the agricultural machinery technological achievements, and the quicker will be promoted scientific and technological achievements. According to the theory of supply and demand, the higher the price of agricultural machinery products, the smaller the demand for agricultural machinery. Hou also confirmed that 
"the price of agricultural machinery has a negative impact on the per acre total power of agricultural machinery [15]." However, the impact of agricultural machinery product prices on the AEL is not significant. On the one hand, the selected indicators used to measure the AEL (such as the total power of agricultural machinery, the original value of agricultural machinery, and the total power of tractors) are stock indicators. On the other hand, because large-scale agricultural machinery transformation and renovation activities were conducted in the 1990s [47], the agricultural machinery that was purchased at that time had not yet been updated during our study period. Therefore, although fluctuating prices of agricultural machinery products may have a great impact on agricultural machinery increment, those price changes have little impact on the stock of agricultural machinery.

Our findings indicate that the relative shortage of rural labor is the prerequisite for the development of agricultural mechanization. Hence, the transfer of the rural labor force not only creates a demand for the development of agricultural mechanization, but also provides the economic foundation for the development of agricultural mechanization. In addition, the education level of farmers also has the following two effects on agricultural production: first, farmers with a higher education level are more likely to accept new things. They will provide more opportunities for migrant workers and earn a higher income. As such, they tend to invest more in agricultural equipment and agricultural mechanization. Second, the achievement of agricultural mechanization requires farmers to master a certain degree of technological knowledge and skills. It is relatively easy to promote advanced agricultural machines in regions where farmers are highly educated. Therefore, the AML and the cultural quality of workers are positively correlated [24].

\section{Conclusions}

Although some studies have investigated the factors affecting the AML in China, the effect of the AEL has not been studied in previous literature. We have modelled the relationship between the AEL and AML using an integrated framework, and therefore, our results confirm the importance of the AEL to the AML. This report can be used to inform the government that the current agricultural machinery purchase subsidy policy must still be strengthened.

In this article, we formulated an integrative framework, using SEM to assess the various factors affecting the AML in China. The results provided solid support for most of our hypotheses. Specifically, the estimated results showed that the AEL had the greatest impact on the AML, and the level of economic development, demographic factors, and benefit factors had not only directly affected the AML but had also indirectly affected the AML through the AEL. In addition, land resource endowment and policy and environmental factors had only an indirect effect on the AML.

Our findings are based on the data available to us. Future research that could enrich our understanding of China's AML could potentially proceed with longer-term empirical research. Additionally, future research should focus on the AML and AEL in hilly areas and promote the fostering of agricultural machinery service organizations, which mainly provide agricultural mechanization services for small farmers. This could be discussed when adjusting the agricultural machinery purchase subsidy policy in the future. Both the agricultural output value per labor and agricultural grain production per labor have a significant impact on the level of agricultural equipment and the level of agricultural mechanization.

Author Contributions: W.L. and R.Z. conceived and designed the experiments, analyzed the data, interpreted the findings, and wrote the draft. K.G. contributed to the results and discussion, and the paper revision. X.W. contributed to the data collection.

Funding: The authors acknowledge the financial supports of the Humanities and Social Sciences projects of the Ministry of Education (No.15YJC630062), the Shaanxi Science and Technology projects (No.2016NY-010), the Fundamental Research Funds for the Central Universities (No. 2452016079) and the Ph.D. Research start-up foundation of Northwest A\&F University (No. 2452015293).

Conflicts of Interest: The authors declare no conflict of interest. 


\section{Appendix A}

Table A1. Data collection process and sources.

\begin{tabular}{|c|c|c|}
\hline Measurable Variables & Query Indexes & Data Sources \\
\hline \multirow{2}{*}{ GDP per capita } & GDP & \multirow{2}{*}{ China Statistical Yearbook } \\
\hline & Population size & \\
\hline \multirow{2}{*}{ Per capita net income of farmers } & Primary Industry GDP & China Statistical Yearbook \\
\hline & Rural laborers & China Rural Statistical Yearbook \\
\hline \multirow{2}{*}{ Primary Industry GDP/Regional GDP } & Primary Industry GDP & \multirow{2}{*}{ China Statistical Yearbook } \\
\hline & Regional GDP & \\
\hline \multirow{2}{*}{ Cultivated area per laborer } & Cultivated area & China Statistical Yearbook \\
\hline & Rural laborers & China Rural Statistical Yearbook \\
\hline \multirow{2}{*}{ Hilly and mountainous area/land area } & Flat area & \multirow{2}{*}{ Chinese natural resources database } \\
\hline & Total land area & \\
\hline \multirow{2}{*}{ Wheat sown area/total sown area of crops } & Wheat sown area & \multirow{2}{*}{ China Rural Statistical Yearbook } \\
\hline & Total sown area of crops & \\
\hline \multirow{2}{*}{ Primary industry practitioners/society practitioners } & Primary industry practitioners & \multirow{2}{*}{ China Rural Statistical Yearbook } \\
\hline & Society practitioners & \\
\hline \multirow{2}{*}{ Labor transfer rate } & Rural laborers & \multirow{2}{*}{ China Rural Statistical Yearbook } \\
\hline & Agricultural workers & \\
\hline Educational degree of rural resident/year & Cultural Composition of Labor Force & China Rural Statistical Yearbook \\
\hline \multirow{2}{*}{$\begin{array}{l}\text { Average subsidy funds per unit area of land over the } \\
\text { years }\end{array}$} & Subsidized funds over the years & China Rural Statistical Yearbook \\
\hline & Cultivated area & China Statistical Yearbook \\
\hline \multirow{2}{*}{$\begin{array}{l}\text { The number of personnel engaged in agricultural } \\
\text { machinery technology, promotion, education, and } \\
\text { training per 10,000 labor force }\end{array}$} & $\begin{array}{c}\text { Number of personnel engaged in agricultural } \\
\text { machinery technology, promotion, education, and } \\
\text { training }\end{array}$ & \multirow[t]{2}{*}{ The Yearbook of Agricultural Mechanization in Chin } \\
\hline & Rural laborers & \\
\hline
\end{tabular}


Table A1. Cont.

\begin{tabular}{|c|c|c|}
\hline Measurable Variables & Query Indexes & Data Sources \\
\hline Fixed base price index of mechanized farm machinery & Fixed base price index of mechanized farm machinery & China Rural Statistical Yearbook \\
\hline \multirow{2}{*}{ Agricultural output value per laborer } & Agricultural output value & \multirow{2}{*}{ China Rural Statistical Yearbook } \\
\hline & Rural labor & \\
\hline \multirow{2}{*}{ Agricultural grain production per laborer } & Total agricultural grain production & \multirow{2}{*}{ China Rural Statistical Yearbook } \\
\hline & Rural laborers & \\
\hline Total power of agricultural machinery & Total power of agricultural machinery & The Yearbook of Agricultural Mechanization in China \\
\hline Original value of agricultural machinery & Original value of agricultural machinery & $\begin{array}{c}\text { National Agricultural Mechanization Statistical } \\
\text { Yearbook }\end{array}$ \\
\hline Total power of tractor & Total power of tractor & $\begin{array}{c}\text { National Agricultural Mechanization Statistical } \\
\text { Yearbook }\end{array}$ \\
\hline Mechanical ploughing level & Mechanical ploughing level & The Yearbook of Agricultural Mechanization in China \\
\hline Mechanical seeding level & Mechanical seeding level & The Yearbook of Agricultural Mechanization in China \\
\hline Mechanical harvesting level & Mechanical harvesting level & The Yearbook of Agricultural Mechanization in China \\
\hline GDP price index of provinces (cities, districts) & GDP price index of provinces (cities, districts) & China Statistical Yearbook \\
\hline Consumer price index of rural residents & Consumer price index of rural residents & China Statistical Yearbook \\
\hline Agricultural machinery price index & Agricultural machinery price index & China Rural Statistical Yearbook \\
\hline
\end{tabular}




\section{References}

1. Liu, Y.; Tian, Z. Analysis on Household income levels affect the demand for farm machinery and equipment. Chin. Rural Econ. 2009, 12, 44-55.

2. Kong, X.; Zhou, Z.; Lu, Y. Exploration and Policy Suggestions of Agricultural Mechanization Road in China. Econ. Rev. 2015, 7, 65-72.

3. Lu, Y.; Zhou, Z.; Zhang, Z.; Kong, X. Institutional Change During Development Process of Agricultural Mechanization in 40 Years of Reform and Opening-up in China. J. Northwest AEF Univ. 2018, 18, 1825.

4. Feng, J.; Fu, Z.; Zheng, X.; Mu, W. Farmers' purchase intention of agricultural machinery, an application of the theory of planned behavior in China. J. Food Agric. Environ. 2010, 8, 751-753.

5. Zhang, X.; Yang, J.; Thomas, R. Mechanization outsourcing clusters and division of labor in Chinese agriculture. Chin. Econ. Rev. 2017, 43, 184-195. [CrossRef]

6. Yang, J.; Huang, Z.; Zhang, X.; Reardon, T. The rapid rise of cross-regional agricultural mechanization services in China. Am. J. Agric Econ. 2013, 95, 1245-1251. [CrossRef]

7. Qiao, F. Increasing wage, mechanization and agriculture production in China. Chin. Econ. Rev. 2017, 46, 249-260. [CrossRef]

8. Wang, X.; Yamauchi, F.; Otsuka, K. Wage Growth, Landholding, and Mechanization in Chinese Agriculture. World Dev. 2016, 86, 30-45. [CrossRef] [PubMed]

9. Zhang, M.; Duan, F.; Mao, Z. Empirical Study on the Sustainability of China's Grain Quality Improvement: The Role of Transportation, Labor, and Agricultural Machinery. Int. J. Environ. Res. Pub. 2018, 15, 271. [CrossRef] [PubMed]

10. Jian, C. Agricultural Mechanization in Southwestern China during Transitional Period: A Case Study. AMA-Agric. Mech. Asia Afr. Lat. Am. 2018, 49, 7-16.

11. Zhao, S.; An, Z. Research on the Development Relationship Between Agricultural Mechanization and New Urbanization. Agro Food Ind. Hi-Tech. 2017, 28, 362-366.

12. Wang, Ou.; Tang, K.; Zheng, H. Effects of Agricultural Machinery on Labor Force Substitution Intensity and Food Output. Chin. Rural Econ. 2016, 12, 46-59.

13. Yiang, Y.; Liu, P.; Li, N. Analysis on Affecting Factors and System of Agricultural Mechanization Development in Northeast China. J. Agrotech. Econ. 2006, 5, 28-33.

14. Lu, B.; Zhang, Z.; Zhu, M. Discrimination and Analysis of Key Influencing Factors for Agricultural Mechanization Development. Trans. Chin. Soc. Agric. Eng. 2008, 24, 114-117.

15. Hou, F. Agricultural Mechanization Propulsion Mechanism Influencing Factors Analysis and Policy Implications. Chin. Rural Sur. 2008, 5, 42-48.

16. Zheng, W.; He, Y.; Cen, Y. Study on Evaluation Methods for Agricultural Mechanization Developing Level Based on Rough Set Theory and Fuzzy Aggregation. Trans. Chin. Soc. Agric. Eng. 2006, 37, 58-61.

17. Yamauchi, F. Rising real wages, mechanization and growing advantage of large farms: Evidence from Indonesia. Food Policy 2016, 58, 62-69. [CrossRef]

18. Bai, R. Thinking on the development of agricultural mechanization during the '13th Five-year' in China. J. Chin. Agric. Mech. 2014, 35, 1-5.

19. Yang, M.; Bai, R. Analysis on the Relationship Between Agricultural Machinery Gross Power and Influence Factors. J. Agric. Mech. Res. 2004, 11, 45-47.

20. Liu, Y.; Tian, Z.; Jiang, X. Study on the Characteristic and Determinations of Agricultural Equipment in China. J. Chin. Agric. Univ. 2005, 4, 54-57.

21. Liu, Y.; Tian, Z. Study on the Determinants of China Agricultural Equipment Level. J. Agrotech. Econ. 2008, 6, 73-79.

22. Yan, T.; Li, L.; Wang, R. Analysis on the Influencing Factors of Agricultural Equipment Level in the Process of Modernization. J. Agrotech. Econ. 2010, 12, 38-43.

23. Yan, C. Determinants of Agricultural Machinery Equipment Level in China. Hebei Agric. Mach. 2014, 9, $45-46$.

24. Yang, M.; Bai, R. Study on Regional Unbalance of Agricultural Mechanization Development in China. Trans. Chin. Soc. Agric. Mach. 2005, 9, 60-63.

25. Yang, M. Study on Agricultural Mechanization and the Enhancement of Agricultural International Competitiveness in China. Ph.D. Thesis, China Agricultural University, Beijing, China, 2003. 
26. Qiu, L.; Wei, G.; Zhao, L. Study on the Setting of Agricultural Mechanization evaluation index system in China. Soc. Sci. J. Shenyang Agric. Univ. 2000, 4, 273-275.

27. Li, M.; Shan, S. Evaluation Index System and Evaluation Standard of Agricultural Mechanization. J. Agric. Mech. Res. 2009, 2, 59-61.

28. Ju, J.; Wang, J. Prediction method for the operation level of agricultural mechanization in Heilongjiang Province. Trans. Chin. Soc. Agric. Eng. 2009, 5, 83-88.

29. Zhang, S.; Feng, S.; Jie, D. Combination prediction of agricultural equipment level based on Shapley value. Trans. Chin. Soc. Agric. Eng. 2008, 6, 160-164.

30. Huang, G.; Han, L.; Liu, X. Establish of evaluation system for integrated agricultural mechanization engineering technology. Trans. Chin. Soc. Agric. Eng. 2012, 16, 74-79.

31. Yang, M.; Bai, R. Regional Comparison of the Development of Agricultural Mechanization in China. Trans. Chin. Soc. Agric. Eng. 2000, 16, 68-72.

32. Lin, W.; Sun, C. Influencing Factors on Private Investment in Agricultural Machinery. Chin. Rural Econ. 2007, 9, 25-32.

33. Zhang, Z.; Zhou, S.; Cao, G. Study on Long-term Needs of Farm Machinery Purchase Subsidy. Issues. Agric. Econ. 2009, 12, 34-41.

34. Tuteja, U. Utilization of agricultural input subsidies by caste visa-vision-scheduled caste farmers in Haryana. Indian J. Agric. Econ 2004, 4, 200-213.

35. Zaigham, A.; Fang, W.; Shahid, H. Risk Assessment of Ex-Post Transaction Cost in Construction Projects Using Structural Equation Modeling. Sustainability 2018, 10, 4017.

36. Zheng, Z.; Yaoqi, Z.; Yali, W. Residents' Support Intentions and Behaviors Regarding Urban Trees Programs: A Structural Equation Modeling-Multi Group Analysis. Sustainability 2018, 10, 377.

37. Olsson, U.H.; Foss, T.; Troye, S.V.; Howell, R.D. The performance of ML, GLS, and WLS estimation in structural equation modeling under conditions of misspecification and nonnormality. Struct. Equ. Model. 2000, 4, 557-595. [CrossRef]

38. Kline, R.B. Principles and Practice of Structural Equation Modelling. J. Am. Statis. Assoc. 2011, 101. [CrossRef]

39. Hair, J.F.; Black, B.; Babin, B.J. Multivariate Data Analysis, 7th ed.; Englewood Cliffs: Prentice Hall, NJ, USA, 2011; pp. 154-170.

40. Fornell, C.; Larcker, D.F. Evaluating structural equation models with unobservable variables and measurement error. Int. J. Res. Mark. 1981, 18, 39-51.

41. Byrne, B.M. Structural Equation Modeling Using AMOS. Basic Concepts, Applications, and Programming, 2nd ed.; Routledge: New York, NY, USA, 2009.

42. Wu, X. Co-integration analysis the level of between agricultural mechanization and that of agricultural equipment in China. Chin. Agric. Mech. 2012, 1, 48-52.

43. Zhu, H.; Tian, Z.; Han, L. Dependence of agricultural mechanization on financial investment. Trans. Chin. Soc. Agric. Eng. 2007, 3, 273-278.

44. Zhang, T. Relying on scientific and technological progress, transform the mode of development, promote the scientific development of agricultural mechanization. Agric. Eng. Tech. 2012, 1, 12-19.

45. Li, N.; Wan, Y. Study on the Macroeconomic Policies Effects of China's Agricultural Machinery Purchase Subsidy. Issues. Agric. Econ. 2010, 12, 79-84.

46. Gao, Y. Subsidies for Purchasing Agricultural Machines, Public Expenditure on Agriculture and Land Productivity. J. Shanxi Financ. Econ. Univ. 2010, 1, 72-78.

47. Li, W.; Xue, C.; Zhu, R. Analysis on production allocative efficiency of agricultural machinery based on frontier theory in China. Trans. Chin. Soc. Agric. Eng. 2012, 3, 38-43.

(C) 2018 by the authors. Licensee MDPI, Basel, Switzerland. This article is an open access article distributed under the terms and conditions of the Creative Commons Attribution (CC BY) license (http:/ / creativecommons.org/licenses/by/4.0/). 